\title{
LIBERAÇÃO DE RESÍDUOS LIGADOS DE ATRAZINA DE SOLOS POR MEIO DE ESTERILIZAÇÃO POR AUTOCLAVAGEM E RADIAÇÃO GAMA ${ }^{(1)}$
}

\author{
L. E. NAKAGAWA ${ }^{(2)} \&$ M. M. ANDRÉA ${ }^{(3)}$
}

\begin{abstract}
RESUMO
Para estudar a influência de microrganismos nos processos de dissipação de pesticidas em solos, os métodos de esteri lização são, particularmente, importantes. Este trabalho, realizado nos laboratórios do Instituto Biológico de São Paulo, em agosto de 1996, avaliou a influência de dois métodos de esterilização de solo - calor úmido (autoclavagem) e radiação $\gamma$ - no processo de liberação de resíduos ligados. Tomaram-se, como exemplos, resíduos ligados do herbicida atrazina em dois tipos de solo (gley húmico e latossolo vermel ho-escuro). Nas amostras de solo submetidas à esterilização por calor úmido, a recuperação dos resíduos previamente ligados como resíduos reextraíveis foi de 5,0 e 5,9 vezes superior à dos controles, não submetidos a qualquer processo de esterilização. Portanto, o próprio método de esterilização liberou os resíduos, o que indica que, para estudar a influência de microrganismos na liberação de resíduos ligados, a autoclavagem não é o método mais adequado. Por outro lado, verificou-se que a radiação $\gamma$ não alterou a recuperação dos resíduos em relação aos controles.
\end{abstract}

Termos de indexação: microrganismos, dissi pação, ${ }^{14}$ C-resíduos ligados.

\section{SUMMARY: RELEASE OF BOUND RESIDUES OF ATRAZINE FROM SOILS THROUGH AUTOCLAVING AND GAMMA RADIATION STERILIZATION}

The sterilization methods are particularly important to study the influence of microorganisms on the pesticide dissi pation in soils. This study, conducted in the laboratories of the Instituto Biológico of São Paulo in august 1996, tested the influence of two methods of soil sterilization - moi st heat (autocl aving) and $\gamma$ radiation - on therel ease of nonextractableor bound residues. It was studied, as example, bound residues of the herbicide atrazine in two types of soil (gley humic and dark red latosol). In the soil samples submitted to the moist heat sterilization, the recovery of the previously bound residues as reextractable residues was 5.6

\footnotetext{
(1) Recebido para publicação em janeiro e aprovado em outubro de 1997.

(2) Bióloga, Estudante de Mestrado em E cologia, IB/USP. Bolsista da Capes e estagiária do Centro de Radioisótopos do Instituto Biológico. Caixa Postal 7 119, CEP 01064-970 São Paulo (SP).

(3) Pesquisador Científico do Centro de Radioisótopos do Instituto Biológico. Caixa Postal 7119, CEP 01064-970 São Paulo (SP). Bolsista do CNPq.
} 
and 5.9 times higher than in the control soils, not submitted to any sterilization process. Therefore, the method itself released the residues, indicating that the autoclaving is not the most appropriatemethod for studies on theinfluence of microorganisms on thereleaseof bound residues. Otherwise, the $\gamma$ radiation did not modify theresidues recovery when compared to the controls.

Index terms: microorganisms, dissipation, ${ }^{14} \mathrm{C}$-bound residues.

\section{INTRODUÇÃO}

O destino de pesticidas nos solos é determinado por fatores químicos, físicos e biológicos. Sabe-se, atualmente, que os microrganismos têm papel preponderante na transformação de pesticidas em solo, visto que seu metabolismo pode acarretar a mineralização completa do pesticida ou a formação de metabólitos.

Durante esse processo de dissi pação, os pesticidas podem reagir com a matéria orgânica do solo de diversas maneiras e, muitas dessas reações, levam à formação de resíduos: (a) resíduos do próprio pesticida e/ou de metabólitos que podem ser extraíveis, (b) resíduos que não são extraíveis, ou resíduos ligados, relativamente estáveis, cujo impacto ambiental é questionável (Andréa, 1992).

Resíduos ligados ou não extraíveis em plantas e solos são definidos como "espécies químicas originadas de pesticidas usados de acordo com as boas práticas agrícol as, que não são extraídos por métodos que não mudem significantemente a natureza química destes resíduos" (Kearney, 1982).

Os resíduos ligados são formados por ligações químicas e/ou físicas entre a molécula do pesticida e a matriz do solo. Sua formação podel evar à di mi nuição da taxa de degradação do pesticida, à perda da sua identidade química (Bartha, 1971) e da atividade biológica (Kaufman, 1976), à alteração na absorção do pesticida por culturas posteriores e organismos do solo, no escoamento superficial ena lixiviação desse pesticida pelo perfil do solo (Calderbank, 1989). Entretanto, resíduos ligados de pesticidas podem ser liberados por processos microbiológicos, mudanças ambientais ou mudanças nas práticas agrícolas (Lichtenstein, 1980; Khan, 1982; Klein \& Scheunert, 1982; Führ, 1987). Como há pesticidas que formam quantidades consideráveis de resíduos ligados, torna-se importante a determinação de sua liberação potencial .

Para estudar a liberação de resíduo ligado de pesticidas por microrganismos, o solo deve ser previamente esterilizado. Esse procedimento é necessário não só para assegurar que a população de microrganismos do solo seja proveniente somente do sol o inóculo, mas também para garantir sol o-controle isento de microrganismos para comparação, possibilitando, dessa forma, identificar a influência dos microrganismos sobre o processo.

Estudos a respeito dos efeitos dos métodos de esterilização sobre diversos fatores, tais como: atividade bacteriana (Tuominen et al., 1994), degradação de pesticidas (Fletcher \& Kaufman, 1980) e formação de resíduo ligado (Mostafa et al., 1982), indicam que os próprios métodos influenciam diferentes processos. Sendo assim, os métodos usados, normalmente para esterilização de solos também devem ser investigados quanto à li beração de resíduos ligados, daí a importância de se analisarem os efeitos desses métodos sobre o comportamento de resíduos de pesticidas ligados no sol o.

Este trabal ho teve como objetivo verificar o efeito de autoclavagem e radiação gama sobre a liberação de resíduos ligados, tomando-se, como exemplos, resíduos ligados do herbicida atrazina em solos.

\section{MATERIAL E MÉTODOS}

Utilizaram-se dois tipos de solo com resíduos ligados do herbicida ${ }^{14} \mathrm{C}$-atrazina (2 cloro-etilamino6-isopropilamino (1,3,5 [14C C]-s-triazina): solo gley húmico $(\mathrm{GH})$, com $\mathrm{pH}=4,6,3,6 \%$ de matéria orgânica, $27,9 \%$ de argila, $63,0 \%$ de areia e latossolo vermel hoescuro (LE), com pH = 5,4, 3,6\% de matéria orgânica, $44,9 \%$ de argila, $40,2 \%$ de areia (Nakagawa et al., 1996). As amostras de solo continham $0,085 \mathrm{kBq}(\mathrm{GH})$ e 0,074 kBq (LE), correspondendo a 0,38 $\mu \mathrm{g}$ e 0,3 $\mu \mathrm{g}$ de atrazina ou metabólitos por grama de solo, como resíduos ligados.

Amostras de $15 \mathrm{~g}$ desses sol os (em triplicata) que continham apenas resíduos ligados foram submetidas a dois métodos de esterilização: um por calor úmido, em autoclave a $120^{\circ} \mathrm{C}$ e 9,8 x $10^{4} \mathrm{~Pa}$ de pressão, por 30 minutos, durante três dias consecutivos, e outro por irradiação, com radiação gama, na dose total de 4,5 Mrad e taxa de dose de 1,5 Mrad h-1.

Tanto as amostras de solos esterilizados como as de controle (não submetidas a nenhum método de esterilização) foram extraídas, exaustivamente, com metanol, por $8 \mathrm{~h}$ em soxhlet. Alíquotas de $25 \mathrm{~mL}$ dos extratos obtidos foram concentradas à secura, ressuspendidas em coquetel de cintilação líquida e quantificadas em espectrômetro de cintilação líquida (Packard 1600 TR). A quantidade de radiocarbono extraível de todas as amostras de solo foi calculada como porcentagem em relação ao radiocarbono presente, inicialmente, como resíduo ligado.

\section{RESULTADOS E DISCUSSÃO}

As quantidades reextraídas dos solos (como porcentagem em relação ao radiocarbono presente, 
inicialmente, como resíduos ligados) foram de: 1,5\%, para as amostras de GH eLE (controles); 1,6 e 1,9\%, respectivamente, para as amostras de GH e LE irradiados, e 7,5 e 8,9\%, respectivamente, para as amostras de GH e LE autoclavados (Quadro 1). Observou-se que, por autodlavagem, as recuperações foram superiores às do controle ou dos irradiados, não tendo sido observada diferença entre os tipos de solo.

A liberação de resíduos ligados pelo calor úmido pode ser atribuída ao efeito da temperatura sobre a estrutura da matéria orgânica. Schnitzer \& Khan (1972) verificaram que o material húmico que compõe o sol o forma uma estrutura polimérica com pontes de hidrogênio de diferentes dimensões moleculares, dando origem a uma peneira mol ecular, com diferentes dimensões de malha, capaz de aprisionar moléculas orgânicas como os pesticidas. Segundo K han (1982), temperaturas el evadas podem provocar a decomposi ção térmica da matéria orgânica, enfraquecendo essa estrutura epermitindo a li beração de resíduos ligados.

Nos solos autoclavados, as porções reextraíveis, embora tenham sido inferiores a $10 \%$, foram de 5,0 e 5,9 vezes superiores, respectivamente, para GH eLE, às dos solos-controles não esterilizados e que continham a população microbiana remanescente ao processo de extração. I sso indica ter o método de esterilização por calor úmido provocado a liberação de resíduos ligados para a forma extraível. Os solos esterilizados por radiação $\gamma$ não apresentaram diferenças consideráveis em relação aos soloscontrol es; portanto, a radiação $\gamma$ não levou à liber ação de resíduo ligado, como também observado por K han \& I varson (1982), em estudo com prometrina.

Estudando a própria formação de resíduo ligado de trifluralina, Mostafa et al. (1982) encontraram mai or quantidade de resíduo ligado em solo autoclavado, evidenciando não ser esse método de esterilização ideal para estudos microbianos de liberação de resíduos ligados, além de contribuir para a formação de resíduo ligado.

Quadro 1. Teor de radiocarbono extraível do solo, após esterilização (em relação ao radiocarbono presente, inicialmente, como resíduo ligado)

\begin{tabular}{lcc}
\hline $\begin{array}{c}\text { Métodos } \\
\text { de Esterilização }\end{array}$ & Glei Húmico & $\begin{array}{c}\text { Latossolo } \\
\text { Vermelho-Escuro }\end{array}$ \\
\hline & & \\
Controle & $1,5 \pm 0,9$ & $1,5 \pm 0,1$ \\
Radiação $\gamma$ & $1,6 \pm 1,6$ & $1,9 \pm 0,5$ \\
Calor úmido & $7,5 \pm 2,3$ & $8,9 \pm 1,0$ \\
\hline
\end{tabular}

\section{CONCLUSÕES}

1. O método de esterilização por calor úmido (autoclavagem) nãose mostrou adequado para estudos de liberação microbiana de resíduos ligados ao solo porque levou à liberação desses resíduos.

2. O método de esterilização por irradiação $\gamma$ mostrou-se mais eficiente, pois esterilizou e não alterou a liberação dos resíduos presentes nos solos.

\section{AGRADE CIMENTOS}

À EMBRARAD (E mpresa Brasileira de Radiações Ltda., São Paulo, S. P.), pelas irradiações das amostras de sol o. À CAPES e ao CN Pq, pela concessão de bolsas às autoras.

\section{LITERATURA CITADA}

ANDRÉA, M.M. Formação e biodisponibilidade de resíduos ligados de $\left[{ }^{14} \mathrm{C}\right]$-lindano e $\left[{ }^{14} \mathrm{C}\right]$-paration em dois solos brasileiros. São Paulo, Instituto de Pesquisas Energéticas e Nucleares/ USP, 1992. 130p. (Tese de Doutorado)

BARTHA, R. Fate of herbicide-derived chloroanilines in soil. J. Agric. Food Chem., Washington, 19:385-387, 1971.

CALDERBANK, A. The occurrence and significance of bound pesticide residues in soil. Rev. Environ. Contam. Toxicol., New York, 108:71-103, 1989.

FLETCHER, C.L. \& KAUFMAN, D.D. Effect of sterilization methods on 3-chloroaniline behaviour in soil. J. Agric. Food Chem., Washington, 28:667-671, 1980.

FÜHR, F. Non-extractable pesticides residues in soil. In: INTERNATIONAL CONGRESS ON PESTICIDE CHEMISTRY, 6., London, Proceedings. London, Blackwell; IUPAC, 1987. p.381-389.

KAUFMAN, D.D. Bound and conjugated pesticide residues. In: KAUFMAN, D.D.; STILL, G.G.; PAULSON, G.D. \& BANDAL, S.K., eds. Bound and conjugated pesticide residues. Washington, American Chemical Society, 1976. p.1-10. (ACS Symposium Series, 29)

KEARNEY, P.C. Definition of non extractable pesticide residues in plants and soils. J. Assoc. Off. Anal. Chem., Washington, 65:1031-1032, 1982.

KHAN, S.U. Bound pesticide residues in soil and plants. Res. Rev., New York, 84:1-25, 1982.

KHAN, S.U. \& IVARSON, K.C. Release of soil bound (nonextractable) residues by various physiological groups of microoganisms. J. Environ. Sci. Health, New York, B17:737749, 1982.

KLEIN, W. \& SCHEUNERT, I. Bound pesticide residues in soil, plants and food with particular emphasis on the application of nuclear techniques. In: IAEA, ed. Agrochemicals: fate in food and environment. Vienna, International Atomic Energy Agency, 1982. p.177-205.

LICHTENSTEIN, E.P. Bound residues in soils and transfer of soil residues in crops. Res. Rev., New York, 76:149-153, 1980.

MOSTAFA, I.Y.; ZAYED, S.M.A.D.; ADAM, Y.M. \& ATTABY, H.S.H. Investigations on trifluralin binding to soil and possible uptake of bound residues by plants. J. Environ. Sci. Health, New York, B17:265-275, 1982. 
NAKAGAWA, L.E.; LUCHINI, L.C.; MUSUMECI, M.R. \& MATALLO, M.B. Behaviour of atrazine in soils of tropical zone. Degradation, mobility and uptake of atrazine residues from soils in a crop rotation system (maize/beans). J. Environ. Sci. Health, New York, B31:203-224, 1996.
SCHNITZER, M. \& KHAN, S.U. Humic substances in the environment. Marcel Dekker, New York, 1972. 327p.

TUOMINEN, L.; KAIRESALO, T. \& HARTIKAINEN, H. Comparison of methods for inhibiting bacterial activity in sediment. Appl. Environ. Microbiol, (s.I.), 3454-3457, 1994. 